\title{
Clinical diagnosis criteria for periodontal disease: an update
}

\begin{abstract}
This article in an updated of its original version was published in the journal intitled "Jornal Brasileiro de Clínica Odontológica Integrada", volume 9, pages 88 and 89, in 2005. Due to improved knowledge concerning human health, and changes in the clinical diagnostic criteria for periodontal diseases that occurred after the study period, the need for some updates became evident.
\end{abstract}

Objective: the present study aimed to update the criteria for clinical diagnosis of periodontal diseases that guide the research in the area of Periodontics and Epidemiology at some Institutions.

Method: A guideline was developed by a Committee of professors, researchers and dentists during the First Seminar on Periodontology in Collective Health held in the city of Feira de Santana, Bahia, Brazil, in the year 2004, after discussion and a main document was approved. The following clinical parameters were used in the discussion: probing depth, the distance between gingival margin and cementum enamel junction measurement, clinical attachment level, gingival redness and gingival bleeding on stimulus. Results: In addition to the clinical periodontal criteria presented in the original article published (2005), other criteria of periodontal diseases severity were presented according to the oral condition of the group of individuals investigated. A sample of 644 pregnant women users of the public health service of the municipality of Santo Antônio de Jesus, Bahia, Brazil were employed to evaluate periodontitis status. The diagnosis followed three criteria:

1. Center for Disease Prevention and Control and American Academy of Periodontology.

2. Gomes-Filho et al. ${ }^{1}$

3. Gomes-Filho et al. modified.

The frequency of periodontitis in the sample varied from $17.24 \%$ to $66.92 \%$.

Conclusions: the results of the present study indicate the need to use different diagnostic criteria of periodontal diseases depending on the type of study to be developed and population investigated. Taking care to use the appropriate diagnostic criteria, besides allowing the standardization of the definition of the diseases, contributes to improving the comparability between the findings of scientific studies in this field of health, since a diversity of clinical criteria exist.

Keywords: diagnosis, periodontitis, periodontal diseases, classification
Volume 9 Issue 5- 2018

Isaac Suzart Gomes-Filho,' Soraya Castro

Trindade,' Johelle de Santana Passos-

Soares, ${ }^{1,2}$ Ana Claudia Moraes Godoy

Figueiredo, ${ }^{3}$ Maria Isabel Pereira Vianna, ${ }^{2}$

Alexandre Marcelo Hintz, ${ }^{4}$ Josicélia Estrela

Tuy Batista,' Géssica Santana Orrico,' Sarah dos Santos Conceição,' Julita Maria Freitas Coelho,' Pedro Nascimento Prates Santos,' Michelle Teixeira Nascimento,' Samilly Silva Miranda,' Michelle Xavier Ramos,' Edla Carvalho Lima Porto,' Carla Alencar Cruz,' Silas Santos Carvalho,' Simone Seixas da Cruz, ${ }^{1,5}$

'Department of Health, Feira de Santana State University, Brazil ${ }^{2}$ Department of Preventive Dentistry, Federal University of Bahia, Brazil

${ }^{3}$ Department of Health Sciences, University of Brasilia, Brazil ${ }^{4}$ Department of Psychology, Faculdade Nobre, Brazil ${ }^{5}$ Department of Epidemiology, Federal University of Recôncavo da Bahia, Brazil

Correspondence: Isaac Suzart Gomes-Filho, Department of Health, Feira de Santana State University, Feira de Santana, Bahia, Brazil, Email isuzart@gmail.com

Received: June 19, 2018 | Published: September 14, 2018

\section{Introduction}

Due to the diversity of clinical criteria exist and the improved knowledge concerning human health, and changes in the clinical diagnostic criteria for periodontal diseases that occurred in the last decades, the need for some updates became evident. Thereby, this present study aimed to update the criteria for clinical diagnosis of periodontal diseases and to develop a guideline by a Committee of professors, researchers and dentists in the area of Periodontics and Epidemiology of the following Brazilian institutions: Research Center, Integrated Practice and Multidisciplinary Investigation (Núcleo de Pesquisa, Prática Integrada e Investigação Multidisciplinar) NUPPIIM of Feira de Santana State University - UEFS, Graduate Program in Collective Health UEFS, Graduate Program in Collective Health of the Public Health Institute and Graduate Program in Dentistry and Health of Dental School of the Federal University of Bahia-UFBA and Graduate Program in Immunology of the Health Sciences Institute of UFBA.

\section{Method}

The elaboration of this guideline was a product of scientific meetings of a Committee of professors, researchers and dentists during the First Seminar on Periodontology in Public Health held in the city of Feira de Santana, Bahia, Brazil, in the year 2004. In 2018, part of this Committee performed the updated of the main document after scientific meetings in the same municipality developing the present updated guideline, considering the performance of these clinical criteria in different investigations employing primary data. Such studies were published in important Journals in the Periodontics topic over more than 10 years. $^{2-12}$

\section{Results}

The following clinical parameters were used to establish the diagnosis criteria: probing depth, the distance between gingival margin and cementum enamel junction measurement, clinical attachment 
level, gingival redness and gingival bleeding on stimulus. The criteria proposed for the clinical diagnosis of the periodontal condition were established according to previous studies on the topic., ${ }^{2,3,13-15}$ It should be emphasized that these criteria are suggestions for diagnosis and may be considered flexible depending on the specificities of each research. It is also suggested that the criteria be adapted depending on the population group to be evaluated and the quality of their oral condition. Furthermore, the training of the researchers, examination of all teeth, and the examination of six sites per tooth are considered ideal conditions for the study. After collecting periodontal clinical parameters, the classification of Periodontal Disease can be defined according to its extent, severity and typology. In this way, the criteria for the diagnostic of periodontal conditions can be determined.

\section{Classification according to periodontitis type:}

1. Chronic Periodontitis - individuals with an amount of destruction consistent with the presence of local factors, such as biofilm, calculus etc. Subgingival calculus is also frequently observed. This condition is more prevalent in adults but may occur in children and adolescents. It has a mild to moderate progression rate, however, periods of rapid progression are also possible. $^{13}$

2. Aggressive Periodontitis - individuals with bone destruction and rapid attachment loss, possible family aggregation. Apart from the presence of periodontitis, the individual is otherwise clinically healthy. The amount of microbial deposits is inconsistent with the severity of periodontal tissue destruction. The localized form begins around puberty, presenting in the first molar and incisors, with interproximal attachment loss in at least two permanent teeth, one of which is a first molar, and involving no more than two other teeth beyond the first molars and incisors. The generalized form usually affects individuals under 30 years of age but may be present in older individuals. The generalized interproximal attachment loss affects at least three other permanent teeth besides the first molars and incisors. $^{13}$

Classification according to diagnosis:

1. Diagnosis of Gingivitis: individual who does not meet all criteria for the presence of Periodontitis and presents gingival redness and bleeding on stimulus in more than $25 \%$ of the sites.

2. Diagnosis of Periodontitis: to determine the diagnosis in this periodontal condition, it is necessary, initially, to define the type of investigation.

3. Study to determine Morbidity Measurements (Prevalence and Incidence): individuals presenting at least one tooth with one or more sites with clinical attachment loss greater than or equal to $3 \mathrm{~mm}^{* *}$.

Association study between Periodontal Disease and Systemic Conditions:

The criteria presented in Chart 01 are indicated to define the presence of periodontitis. The diagnosis of periodontitis is defined with the clinical parameters: probing depth, clinical attachment level and bleeding upon probing. In addition, the severity levels of periodontitis are also determined according to the Table below.

To clarify the use of above mentioned criteria, a sample of 644 pregnant women users of the public health service of the municipality of Santo Antônio de Jesus, Bahia, Brazil were employed to evaluate periodontitis status. In addition to these criteria, the proposed criterion by the Center for Disease Prevention and Control and American Academy of Periodontology. The frequency of periodontitis in the sample varied from $17.24 \%$ to $66.92 \%$. In the same manner, the periodontitis severity levels varied in accordance with the criterion employed (Figure 1 and 2).

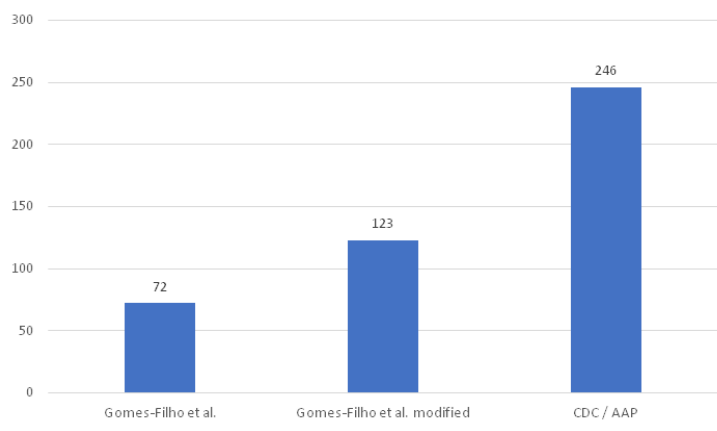

Figure I Number of pregnant women with periodontitis diagnosis.

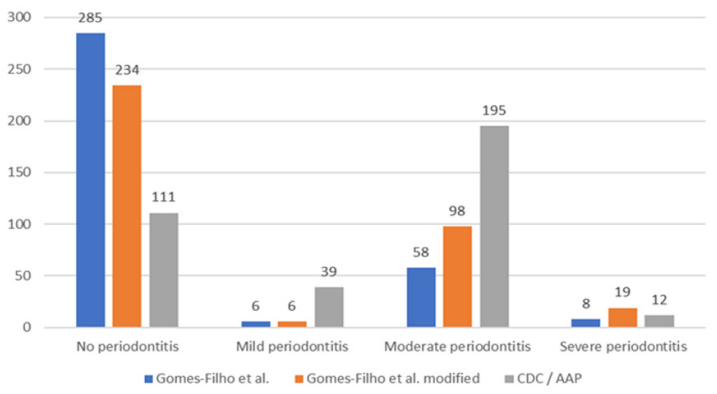

Figure 2 Number of pregnant women in accordance with periodontitis severity levels.

Table I Criteria for diagnosis of periodontitis according to its severity level

Diagnostic criteria for periodontitis, according to Gomes-Filho et al., ${ }^{4}$ and Gomes-Filho et al., modified*

\begin{tabular}{|c|c|c|c|c|}
\hline Severity Level & \multicolumn{2}{|c|}{ Probing Depth (PD) } & $\begin{array}{l}\text { Clinical } \\
\text { Attachment } \\
\text { Level }\end{array}$ & $\begin{array}{l}\text { Bleeding Upon } \\
\text { Probing }\end{array}$ \\
\hline $\begin{array}{l}\text { Severe } \\
\text { Periodontitis }\end{array}$ & $\begin{array}{l}\geq 4 \\
\geq 2 *\end{array}$ & $\begin{array}{l}\text { teeth with } \geq \text { I } \\
\text { site with } \\
P D \geq 5 \mathrm{~mm}\end{array}$ & $\begin{array}{l}C A L \geq 5 \mathrm{~mm} \\
\text { on the same } \\
\text { site }\end{array}$ & $\begin{array}{l}\text { Bleeding upon } \\
\text { stimulus }\end{array}$ \\
\hline $\begin{array}{l}\text { Moderate } \\
\text { Periodontitis }\end{array}$ & $\begin{array}{l}\geq 4 \\
\geq 2 *\end{array}$ & $\begin{array}{l}\text { teeth with } \geq 1 \\
\text { site with } P D \geq 4 \\
\mathrm{~mm}\end{array}$ & $\begin{array}{l}C A L \geq 3 \mathrm{~mm} \\
\text { on the same } \\
\text { site }\end{array}$ & $\begin{array}{l}\text { Bleeding upon } \\
\text { stimulus }\end{array}$ \\
\hline $\begin{array}{l}\text { Mild } \\
\text { Periodontitis }\end{array}$ & $\begin{array}{l}\geq 4 \\
\geq 2 *\end{array}$ & $\begin{array}{l}\text { teeth with } \geq \text { I } \\
\text { site with } P D \geq 4 \\
\mathrm{~mm}\end{array}$ & $\begin{array}{l}C A L \geq I \mathrm{~mm} \\
\text { on the same } \\
\text { site }\end{array}$ & $\begin{array}{l}\text { Bleeding upon } \\
\text { stimulus }\end{array}$ \\
\hline
\end{tabular}

No

Periodontitis Individuals who were not included in the previous groups

*The difference between the last two criteria is only the minimum number of teeth considered: at least 2 teeth for the criterion Gomes-Filho et al., ${ }^{7}$ modified.

\section{Final considerations}

The present study suggests the need to use different diagnostic criteria of periodontal diseases depending on the type of study to be developed and population investigated. The improvement of several researches in the topic of periodontal condition and systemic disease has increased and the comparability among the investigations 
is necessary. However, due to the diversity of clinical criteria for periodontal diagnosis the research cannot be comparable. This guideline was developed to help the researcher to choose the best periodontal disease clinical criteria, taking care to use the appropriate diagnostic criteria, besides allowing the standardization of the definition of the diseases, contributes to improving the comparability between the findings of scientific studies in this field of health.

\section{Acknowledgments}

None.

\section{Conflict of interest}

The author declares that there is no conflict of interest.

\section{References}

1. Gomes-Filho IS. Criteria for clinical diagnosis of periodontal disease Jornal Brasileiro de Clínica Odontológica Integrada e Saúde Bucal Coletiva. 2005;9:88-89.

2. Trindade SC, Gomes-Filho IS, Meyer RJ, et al. Serum antibody levels against Porphyromonas gingivalis extract and its chromatographic fraction in chronic and aggressive periodontitis. Journal of the International Academy of Periodontology. 2008;10(2):50-58.

3. Page RC, Eke PI. Case definitions for use in population-based surveillance of periodontitis. J Periodontol. 2007;78(75):1387-1399.

4. Eke PI, Page RC, Wei L. Update of the case definitions for populationbased surveillance of periodontitis. J Periodontol. 2012;83(12):14491454.

5. Cruz SS, Costa Mda C, Gomes-Filho IS. Contribution of periodontal disease in pregnant women as a risk factor for low birth weight. Community Dent Oral Epidemiol. 2009;37(6):527-533.
6. Passos-Soares JS, Gomes-Filho IS, Vianna MI, et al. Outcome Measurements in Studies on the Association Between Osteoporosis and Periodontal Disease. J Periodontol. 1970;81(12):1773-1780.

7. Gomes-Filho IS, Freitas Coelho JM, da Cruz SS, et al. Chronic periodontitis and C-reactive protein levels. $J$ Periodontol. 2011;82(7):969-978.

8. Passos JS, Vianna MI, Gomes-Filho IS, et al. Osteoporosis/osteopenia as an independent factor associated with periodontitis in postmenopausal women: a case-control study. Osteoporos Int. 2013;24(4):1275-1283.

9. Souza LM, Cruz SS, Gomes-Filho IS, et al. Effect of maternal periodontitis and low birth weight-A case control study. Acta Odontol Scand.2015;74(1):1-8.

10. Gomes-Filho IS. Periodontal disease as a risk factor for acute myocardial infarction. EC Dental Science. 2017;10(2):62-71.

11. Passos-Soares JS, Vianna MIP, Gomes-Filho IS, et al. Association between osteoporosis treatment and severe periodontitis in postmenopausal women. Menopause. 2017;24(7):789-795.

12. Souza AJ, Gomes-Filho IS, Silva CALD. Factors associated with dental caries, periodontitis and intra-oral lesions in individuals with HIV/AIDS. AIDS Care. 2017;30(5):578-585.

13. Armitage GC. Development of a classification system for periodontal diseases and conditions. Ann Periodontol. 1999;4(1):1-6.

14. Lopez NJ, Smith PC, Gutierrez J. Higher risk of preterm birth and low birth weight in women with periodontal disease. $J$ Dent Res. 2002;81(1):58-63.

15. Lopez NJ, Smith PC, Gutierrez J. Periodontal therapy may reduce the risk of preterm low birth weight in women with periodontal disease: a randomized controlled trial. J Periodontol. 2002;73(8):911-924. 